\title{
Microrganismos potenciais e incremento de biomassa em grama esmeralda (Zoysia japonica Steud.)
}

A demanda emergente para a diminuição da dependência de fertilizantes minerais e da necessidade para o desenvolvimento de uma agricultura sustentável aponta o uso de microrganismo como alternativa viável ao produtor. Objetivou-se selecionar potenciais promotores de crescimento e método de inoculação de plantas de grama esmeralda os comparando com a adubação mineral. Nesta pesquisa foram testados nove microrganismos em delineamento experimental inteiramente casualizado. No primeiro ensaio disposto em arranjo fatorial $8 \times 2$ (controle/não inoculado, inoculado com Pseudomonas fluorescens (BRM32111), inoculado com Burkholderia pyrrocinia (BRM32113), inoculados com Pseudoruegeria sabulilitoris strain GJMS-35 (R-92), inoculados com Bacillus thuringiensis YBT-1518 (R-61), inoculados com Bacillus thuringiensis YBT-1518 (R-58), inoculado com mix composto por BRM $32111+B R M 32113$ e inoculados com mix de Trichoderma asperellum (UFRA-T.06, UFRA-T.09, UFRA-T.12, e UFRA-T.52) em dois métodos de aplicação, rega e imersão), com quatro repetições, totalizando 64 unidades experimentais. O segundo ensaio, testou-se o desempenho do melhor método e melhor microrganismo em resposta à aplicação da adubação mineral em delineamento inteiramente casualizado, em esquema fatorial $4 \times 2$ (calcário (sem NPK), calcário+NPK (ureia, superfosfato triplo e cloreto de potássio), NPnK (ureia, fosfato de Araxá e cloreto de potássio) e substrato (solo sem NPK/sem calagem); com e sem inoculação) com cinco repetições. O método de aplicação por rega, independente do isolado, proporcionou aumento de $65 \%$ em matéria seca total, enquanto que por imersão o aumento foi em $35 \%$ em relação ao controle. Maiores acréscimos foram alcançados por BRM 32113 , com ganhos de $156 \%$ e $92 \%$ em matéria seca de raiz e altura de plantas, respectivamente, em relação ao controle. Também foram observados acréscimos na área de cobertura verde do solo e teores de nutrientes em folha, favorecidos pela inoculação bacteriana.

Palavras-chave: Rizobactérias; Método de inoculação; Sustentabilidade.

\section{Potential microorganisms and biomass increase in emerald grass (Zoysia japonica Steud.)}

\begin{abstract}
The emerging demand for decreasing dependence on mineral fertilizers and the need for the development of sustainable agriculture points to the use of microorganisms as a viable alternative to the producer. The aim was to select potential growth promoters and method of inoculation of emerald grass plants comparing them with mineral fertilization. Nine microorganisms were tested in a completely randomized experimental design. In the first assay arranged in an $8 \times 2$ factorial arrangement (control / uninoculated, inoculated with Pseudomonas fluorescens (BRM32111), inoculated with Burkholderia pyrrocinia (BRM32113), inoculated with Pseudoruegeria sabulilitoris strain GJMS-35 (R-92), inoculated with Bacillus thuringiensis YBT- 1518 (R(BRM32111), inoculated with Burkholderia pyrrocinia (BRM 32113 ), inoculated with Pseudoruegeria sabulilitoris strain GJMS-35 (R-92), inoculated with Bacillus thuringiensis YBT- 1518 (R61), inoculated with Bacillus thuringiensis YBT-1518 (R-58), inoculated with a mix composed of BRM32111 + BRM 32113 and inoculated with a Trichoderma asperellum mix (UFRA-T.06, UFRA-
T.09, UFRA- T.12, and UFRA-T.52) in two application methods, watering and soaking), with four replications, totaling 64 experimental units. The second trial tested the performance of the best method and best microorganism in response to the application of mineral fertilization in a completely randomized design, in a $4 \times 2$ factorial scheme (limestone (without NPK), limestone + NPK (urea, triple superphosphate and potassium chloride), NPnK (urea, Araxa phosphate and potassium chloride) and substrate (soil without NPK/liming), with and without inoculation) with five replications. Irrigation application method, independent of the isolate, provided $65 \%$ increase in total dry matter, while by immersion the increase was $35 \%$ in relation to the control. Higher increases were achieved by BRM 32113 , with gains of $156 \%$ and $92 \%$ in root dry matter and plant height, respectively, compared to control. There were also increases in green soil cover and leaf nutrient content, favored by bacterial inoculation.
\end{abstract}

Keywords: Rhizobacteria; Inoculation method; Sustainability.

Topic: Desenvolvimento, Sustentabilidade e Meio Ambiente

Reviewed anonymously in the process of blind peer.

Vanessa dos Santos Araújo (iD

Instituto Federal do Pará, Brasil

http://lattes.cnpq.br/6783842235724850

http://orcid.org/0000-0002-2546-283X

vanessa.st.araujo@gmail.com

Gisele Barata da Silva (D)

Universidade Federal Rural da Amazônia, Brasil

http://lattes.cnpq.br/7941075213053812

http://orcid.org/0000-0002-6064-7864

giselebaratasilva@gmail.com

Jessivaldo Rodrigues Galvão (ic

Universidade Federal Rural da Amazônia, Brasil

http://lattes.cnpq.br/0013591065769741

http://orcid.org/0000-0003-4242-6555

jessigalvao50@gmail.com

DOI: 10.6008/CBPC2179-6858.2020.001.0028
Received: 12/12/2019

Approved: 11/01/2020

\author{
Cristine Bastos do Amarante (iD) \\ Museu Paraense Emílio Goeldi, Brasil \\ http://lattes.cnpq.br/4101983776191966 \\ http://orcid.org/0000-0002-8602-8180 \\ cbamarante@museu-goeldi.br \\ Walter Vellasco Duarte Silvestre (iD) \\ Universidade Federal Rural da Amazônia, Brasil \\ http://lattes.cnpq.br/0450053479016561 \\ http://orcid.org/0000-0002-3821-769X \\ waltervellasco@gmail.com \\ Deyvison Andrey Medrado Gonçalves (D) \\ Universidade Federal Rural da Amazônia, Brasil \\ http://lattes.cnpq.br/6099077031354248 \\ http://orcid.org/0000-0002-2664-0749 \\ deyvisonmedrado@gmail.com
}

Referencing this:

ARAÚJO, V. S.; SILVA, G. B.; GALVÃO, J. R.; AMARANTE, C. B.; SILVESTRE, W. V. D.; GONÇALVES, D. A. M.. Microrganismos potenciais e incremento de biomassa em grama esmeralda (Zoysia japonica Steud.). Revista Ibero Americana de Ciências Ambientais, v.11, n.1, p.309-320, 2020. DOI: http://doi.org/10.6008/CBPC2179-

$\underline{6858.2020 .001 .0028}$ 


\section{INTRODUÇÃO}

A adubação mineral representa uma prática usual para a manutenção dos gramados, que por vezes apresentam um crescimento lento, porém o uso intensivo desses produtos está associado a riscos ambientais, o que levanta uma preocupação em torno da poluição gerada e os impactos ambientais, como a possibilidade de eutrofização, acidificação dos solos e contaminação dos lençóis freáticos, pelo acúmulo de compostos nitrogenados (GUPTA et al., 2012). Considerando ainda que os usos de adubos químicos, em vias de regra, podem ocasionar queimaduras no gramado, depreciando o aspecto visual e físico do gramado. Isto ocorre devido à alta higroscopicidade característica de determinados fertilizantes, que possuem grande capacidade de absorver água do ar, mesmo em condições de baixa umidade relativa do ar, podendo também absorver água da folha da grama, causando uma queima desta pela desidratação rápida (GODOY et al., 2003).

Neste sentido, surge o interesse em alternativas mais sustentáveis, visando a diminuição ou substituição do uso de produtos químicos, fato esse que se deve a uma maior conscientização sobre a preservação do meio ambiente (BETTIOL et al., 2009). Alinhado a este interesse, o uso de microrganismos promotores do crescimento de plantas apresentam grande potencialidade de uso. Bactérias e fungos que exercem efeitos benéficos, disponibilizando nutrientes para as plantas, seja pela solubilização de fosfato inorgânico, pela produção de fitormônios ou pelo maior crescimento das raízes, favorecendo a absorção de água e nutrientes (MACHADO et al., 2012).

Fungos do gênero Trichoderma são uns dos principais microrganismos de importância para o aumento do crescimento vegetal. Chagas et al. (2017), ao testar a ação de Trichoderma spp. inoculadas em solo fertilizado com fosfato natural, afirma efeitos favoráveis na promoção do crescimento e eficiência no uso do fósforo em plantas de arroz em ambiente controlado.

A ação benéfica de rizobactérias também são destacadas por Lopes et al. (2018), estes autores relatam acréscimos em variáveis fisiológicas, morfológicas e bioquímicas em Brachiaria (Syn. Urochloa) brizantha cv. BRS Piatã inoculadas com Pseudomonas fluorescens (BRM32111) e Burkholderia pyrrocinia (BRM32113). A inoculação de plantas jovens de açaizeiro com Bacillus thuringiensis YBT-1518 e Pseudoruegeria sabulilitoris strain GJMS-35, promoveram aumento no crescimento, acúmulo de biomassa, maiores teores de nutrientes bem como melhorias em parâmetros fisiológicos, quando comparadas ao controle (CASTRO, 2018).

Deste modo, o uso de microrganismos promotores de crescimento pode acelerar o crescimento de plantas de grama esmeralda, pode aumentar a disponibilidade de nutrientes essenciais, contribuindo para o manejo da fertilidade do solo, favorecendo o crescimento e desenvolvimento vegetal. Objetivou-se selecionar isolados eficientes na promoção do crescimento de grama esmeralda, identificar o melhor método de inoculação, utilizando rizobactérias e fungos do gênero Trichoderma, bem como seu desempenho mediante o uso da adubação mineral. 


\section{MATERIAIS E MÉTODOS}

Este trabalho foi desenvolvido em dois ensaios (I e II), conduzidos em condições controladas de casa de vegetação.

Ensaio I. Neste este ensaio objetivou-se a obtenção de um isolado e o método de inoculação mais promissor a promoção de crescimento de grama esmeralda (Zoysia japonica Steud.). O experimento foi conduzido em casa de vegetação na Universidade Federal Rural da Amazônia, Belém, Pará, Brasil. As mudas utilizadas foram provenientes de placas comerciais, as quais foram desmembradas em plugs de $25 \mathrm{~cm}^{2}$, cultivados em vasos de polietileno com 2,5 L de volume, preenchidos com substrato (Latossolo Amarelo Distrófico típico - pH, 4,63; matéria orgânica, $22,90 \mathrm{~g} / \mathrm{dm}^{3} ; \mathrm{P}, 3,60 \mathrm{mg} / \mathrm{dm}^{3}$; Nitrogênio, $1,8 \mathrm{~g} / \mathrm{dm}^{3} ; \mathrm{K}, 0,034$ $\left.\mathrm{cmol}_{c} / \mathrm{dm}^{3} ; \mathrm{Ca}^{2+}, 0,19 \mathrm{cmol}_{c} / \mathrm{dm}^{3} ; \mathrm{Al}^{+}, 1,50 \mathrm{cmol}_{c} / \mathrm{dm}^{3} ; \mathrm{Mg}^{2+}, 0,66 \mathrm{cmol}_{c} / \mathrm{dm}^{3} ; \mathrm{H}+\mathrm{Al}, 9,63 \mathrm{cmol}_{c} / \mathrm{dm}^{3}\right)$, submetido a calagem correspondente a $3 \mathrm{t} \mathrm{ha}^{-1}$ de calcário dolomítico, conforme Silva (2003).

Foram utilizados os microrganismos: Pseudomonas fluorescens (BRM32111); Burkholderia pyrrocinia (BRM32113); Pseudoruegeria sabulilitoris strain GJMS-35 (R-92); Bacillus thuringiensis YBT-1518 (R-61); Bacillus thuringiensis YBT-1518 (R-58); mix bacteriano composto por Pseudomonas fluorescens (BRM32111) e Burkholderia pyrrocinia (BRM32113) e Mix de Trichoderma asperellum (UFRA-T.06, UFRA-T.09, UFRA-T.12, e UFRA-T.52), fornecidos pelo Laboratório de Proteção de Plantas da Universidade Federal da Amazônia, e originalmente selecionados, conforme Silva et al. (2012). Todos os microrganismos foram cultivado separadamente, inclusive os utilizados na composição dos mix's, as rizobactérias foram cultivadas em placas de Petri contendo meios de cultura sólidos 523, cuja suspensão foi ajustada a $550 \mathrm{~nm}$ de absorvância utilizando um espectrofotómetro ( $\mathrm{A} 550=0,1$ correspondendo a $10^{8} \mathrm{CFU} \cdot \mathrm{mL}^{-1}$ ) e os quatro isolados de Trichoderma foram cultivados em meio de cultura BDA, cuja suspensão de conídios foi ajustada para $10^{8}$ UFC. $\mathrm{mL}^{-1}$ utilizando uma câmara de Neubauer, conforme Rêgo et al. (2014).

Os microrganismos foram aplicados por dois métodos de inoculação: Rega (fornecimento de suspensão microbiana na forma de água de rega $(50 \mathrm{~mL})$ a ser despejado sobre os plugs já plantados) e Imersão (imergir plugs de grama esmeralda em $50 \mathrm{~mL}$ das suspensões microbianas por 30 minutos), em seguida os plugs foram plantados.

Aos 45 dias após o plantio foram determinados os seguintes parâmetros: altura de plantas (AP), em $\mathrm{cm}$, com o auxílio de régua graduada; matéria seca das aparas (MSA), em g.vaso-1; matéria seca de estolão (MSE), em g.vaso-1; matéria seca de raízes (MSR), em g.vaso-1 ${ }^{-1}$ obtidos por meio da secagem em estufa (65 ${ }^{\circ}$ C) até massa constante. A matéria seca total, em g vaso-1, foi obtida a partir da soma dos valores da MSA, MSR e MSE e o índice de coloração verde (ICV) da folha, obtido através de um aparelho portátil Chlorophyll Meter, modelo SPAD-502 (Soil and Plant Analysis Development) posicionado a área de medida no centro da lâmina foliar totalmente expandida (BACKES et al., 2010).

O delineamento experimental foi inteiramente casualizado em arranjo fatorial $8 \times 2$ (controle/não inoculado, inoculado com P. Fluorescens (BRM32111), inoculado com B. pyrrocinia (BRM32113), inoculados com P. sabulilitoris strain GJMS-35 (R-92), inoculados com B. thuringiensis YBT-1518 (R-61), inoculados com 
B. thuringiensis YBT-1518 (R-58), inoculado com mix composto por P. fluorescens (BRM32111) e B. pyrrocinia (BRM32113) e inoculados com mix de T. asperellum (UFRA-T.06, UFRA-T.09, UFRA-T.12, e UFRA-T.52) em dois métodos de aplicação, rega e imersão), com quatro repetições, totalizando 64 unidades experimentais.

As médias de matéria seca total para os dois métodos de inoculação foram submetidas a análise de variância e as comparações das médias foram realizadas utilizando o teste Tukey $(p \leq 0.05)$. A análise de componentes principais (PCA), foi empregada para examinar as variações nas variáveis de resposta e verificar quais destes contribuíram na distinção dos tratamentos obtendo, portanto, duas variáveis de análise que capture a maior variação nos tratamentos.

Ensaio II. Neste ensaio, o desempenho da rizobactéria de B. pyrrocinia (BRM32113) e o método de inoculação por rega selecionados conforme o ensaio I, foi comparado com e sem o uso da adubação mineral no solo. O experimento foi conduzido em casa de vegetação no munícipio de Santa Izabel do Pará, Pará, Brasil. As mudas foram adquiridas conforme o ensaio I, porém, foram desmembradas em discos de $9 \mathrm{~cm}$ de diâmetro, de forma a preencher toda area superficial do vaso, preenchidos com substrato (Latossolo Amarelo - pH, 4,09; matéria orgânica, 27,45 g/ $\mathrm{dm}^{3} ; \mathrm{P}, 4,35 \mathrm{mg} / \mathrm{dm}^{3}$; Nitrogênio, $0,72 \mathrm{~g} / \mathrm{dm}^{3} ; \mathrm{K}, 0,66 \mathrm{cmol} / \mathrm{cm}^{3} ; \mathrm{Ca}^{2+}$, $\left.0,21 \mathrm{cmol}_{c} / \mathrm{dm}^{3} ; \mathrm{Al}^{+}, 1,48 \mathrm{cmol}_{c} / \mathrm{dm}^{3} ; \mathrm{Mg}^{2+}, 0,55 \mathrm{cmol}_{c} / \mathrm{dm}^{3} ; \mathrm{H}+\mathrm{Al}, 7,36 \mathrm{cmol}_{c} / \mathrm{dm}^{3}\right)$, em seguida foi removido um disco central de 5,4 cm de diâmetro para detereminação da área de cobertura verde do solo.

Foi determinada a área de cobertura verde do solo por meio de imagens digitais, capturadas quinzenalmente após o plantio, com o auxílio de uma câmera digital modelo Samsung WB30F, de 16.2 megapixels, fixada em uma estrutura denominada caixa de luz $(0,5 \times 0,6 \mathrm{~m})$, semelhante à confeccionada por Peterson et al. (2011). As imagens foram analisadas pelo programa QUANT ${ }^{\circ}$ de acordo com Santos Junior, (2011) e teores de N (nitrogênio), P (fósforo), K (potássio), Ca (Cálcio) e Mg (Magnésio), por meio de amostras das folhas submetidas à digestão nítrico-perclórica (TEDESCO et al., 1995). Os teores de Ca e Mg foram determinados por espectrofotometria de absorção atômica; o teor de K, por fotometria de chama; e o P por espectrofometria e $\mathrm{N}$ por digestão sulfúrica e determinados pelo método Kjeldahl, conforme descrito por Silva (2009).

O delineamento experimental foi inteiramente casualizado em arranjo fatorial 4×2, (calcário (sem NPK), calcário + NPK (ureia, superfosfato triplo e cloreto de potássio), NP K (ureia, Fosfato de Araxá e cloreto de potássio) e substrato (solo sem NPK/sem calagem) com e sem inoculação de B. pyrrocinia aplicada por rega), com cinco repetições, totalizando 40 unidades experimentais. As doses de NPK foram $50 \mathrm{~kg}$ de N de $\mathrm{ha}^{-1}, 140 \mathrm{~kg} \mathrm{P}_{2} \mathrm{O}_{5} \mathrm{ha}^{-1}$ e $100 \mathrm{~kg} \mathrm{~K}_{2} \mathrm{O} \mathrm{ha}^{-1}$, respectivamente, conforme Cravo et al. (2007). Os dados foram submetidos à análise de variância (ANOVA) e as comparações das médias de cada indivíduo, foram realizadas utilizando o teste Tukey $(p \leq 0.05)$.

\section{RESULTADOS}

Ensaio I. Os dois métodos de aplicação de microrganismos promoveram o crescimento da grama. A aplicação por rega aumentou em média de $65 \%$ em matéria seca total enquanto que por imersão o aumento foi $35 \%$ superior, em relação às plantas controle (Tabela 1). A rizobactéria B. pyrrocinia (BRM32113) 
promoveu o maior acúmulo de matéria seca total, em média de $122 \%$ e $64 \%$ por rega e imersão, respectivamente (Tabela 1$)$.

Tabela 1: Efeito dos microrganismos e métodos de inoculação na produção de matéria seca total de grama esmeralda (Z. Japonica Steud.).

\begin{tabular}{|l|l|l|}
\hline \multicolumn{2}{|l|}{ Matéria seca total $\left(\mathrm{g} \mathrm{vaso}^{-1}\right.$ ) } & Método de inoculação \\
\hline Tratamentos & Rega & Imersão \\
\hline Controle & $8,57 \pm 0,29$ e & $8,88 \pm 0,32 \mathrm{~d}$ \\
\hline BRM32111 & $17,45 \pm 0,57 \mathrm{~b}^{*}$ & $12,91 \pm 0,51 \mathrm{~b}$ \\
\hline BRM32113 & $19,04 \pm 0,62 \mathrm{a}^{*}$ & $14,55 \pm 0,68 \mathrm{a}$ \\
\hline R-92 & $13,21 \pm 0,58 \mathrm{c}$ & $12,52 \pm 0,76 \mathrm{~b}$ \\
\hline R-61 & $12,47 \pm 0,19 \mathrm{~cd}^{*}$ & $10,94 \pm 0,81 \mathrm{c}$ \\
\hline R-58 & $13,54 \pm 0,13 \mathrm{c}^{*}$ & $10,80 \pm 0,49 \mathrm{c}$ \\
\hline Mix Bacteriano & $11,50 \pm 1,08 \mathrm{~d}$ & $11,57 \pm 0,64 \mathrm{bc}$ \\
\hline Mix Trichoderma & $11,44 \pm 0,53 \mathrm{~d}^{*}$ & $10,32 \pm 0,78 \mathrm{c}$ \\
\hline Média & $13,41 \pm 3,38^{*}$ & $11,56 \pm 1,75$ \\
\hline CV\% & $\mathbf{7 , 6 3}$ & $\mathbf{4 , 8 8}$ \\
\hline
\end{tabular}

Médias seguidas de asteriscos registram a comparação entre métodos de inoculação. Médias seguidas pela mesma letra na coluna, não diferem entre si $(p \leq 0.05$, Teste Tukey). BRM32111= $P$. fluorescens; $\mathrm{BRM} 32113=B$. $p y r r o c i n i a ; \mathrm{R}-92=P$. sabulilitoris strain GJMS-35, R-61=B. thuringiensis YBT-1518, R-58=B. thuringiensis YBT-1518, BRM32111+BRM32113= mix bacteriano e mix de T. asperellum= UFRA-T.06+ UFRA-T.09+ UFRA-T.12+ UFRA-T.52.

Os dois primeiros componentes principais ( $P C^{\prime}$ 's) foram responsáveis por $88 \%$ da variação total dos dados. O PC1 foi responsável por 77\% de análise e o PC2, responsável por $11 \%$ da informação contida no conjunto original das cinco variáveis (Figura 1).

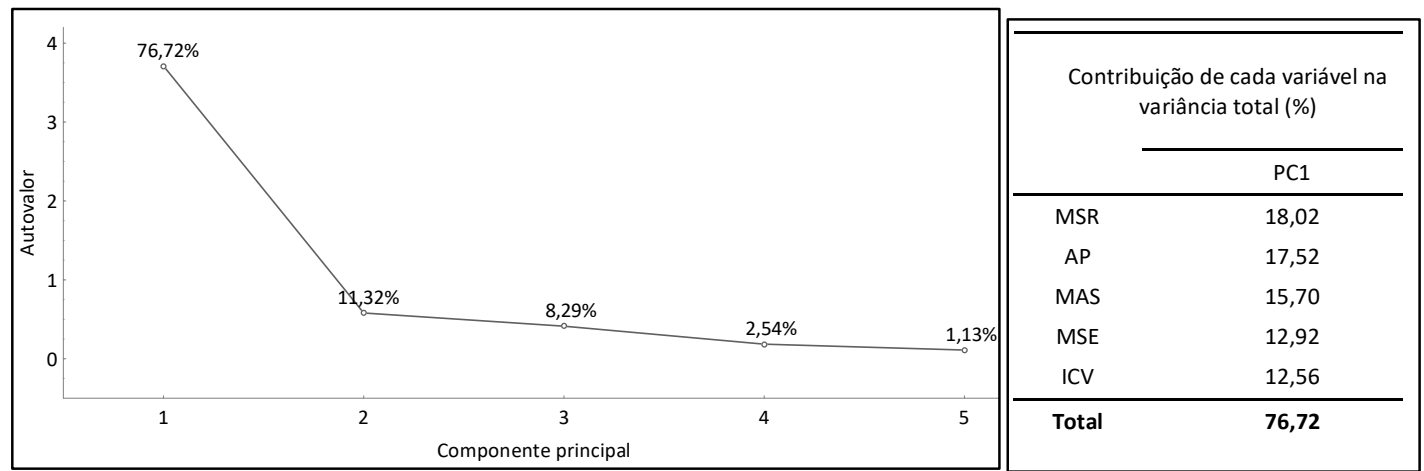

Figura 1: Proporção da variação no conjunto de dados explicada pelo componente principal (PC) e contribuição de cada variável (matéria seca de raiz (MSR), altura de plantas (AP), matéria seca das aparas (MSA), matéria seca de estolão (MSE) e índice de coloração verde (ICV)) para explicação da variância total pelo método 'scree plot'. Método de inoculação por rega.

As variáveis MSR e AP explicam maior parte da variância total dos dados, contribuindo cada uma com 18\%. As variáveis MSA, MSE e ICV apresentam baixo poder discriminatório entre as variáveis determinadas, com contribuições a variância total menor que, em média, 15\%, permitindo o descarte dessas variáveis, favorecendo a otimização do conjunto original (Figura 1).

Verifica-se uma separação natural pela formação de grupos distintos, um grupo é composto pelo tratamento controle contido na elipse menor e outro grupo formado pelas rizobactérias $P$. fluorescens (BRM32111) e B. pyrrocinia (BRM32113), contidos na elipse maior. Os demais tratamentos permanecem dispersos, configurando pouca relação com as variáveis analisadas (Figura 2). As variáveis de análise MSR e AP apresentaram contribuições similares para o CP1, representadas por vetores próximos ao círculo unitário, 
de maior comprimento, alinhadas ao eixo da PC1 e com pequeno ângulo em relação ao eixo das abscissas

(Figura 2).

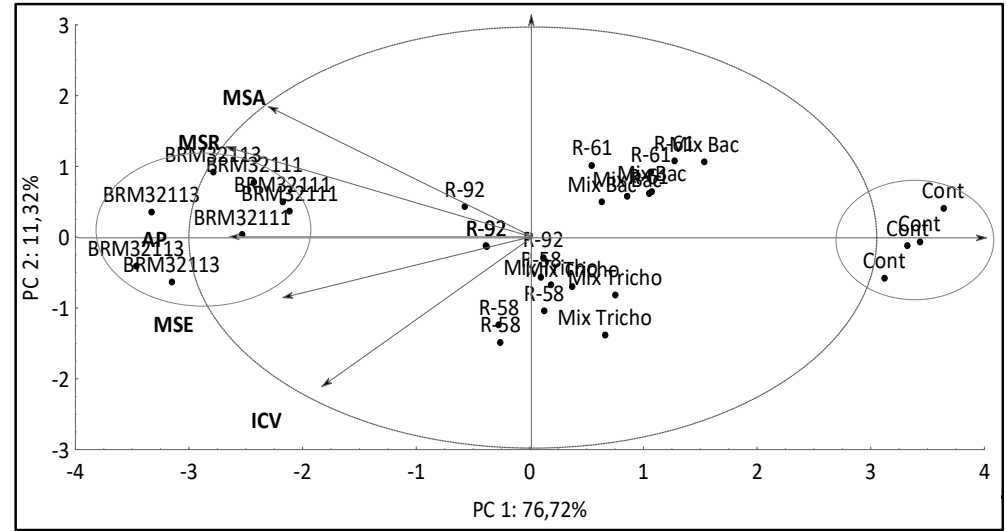

Figura 2: Escores das duas primeiras componentes principais das variáveis de análise (matéria seca de raiz (MSR), altura de plantas (AP), matéria seca das aparas (MSA), matéria seca de estolão (MSE) e índice de coloração verde (ICV)) em diferentes tratamentos: Controle, P. fluorescens (BRM32111), B. pyrrocinia (BRM32113), P. sabulilitoris strain GJMS-35 (R-92), B. thuringiensis YBT-1518 (R-61), B. thuringiensis YBT-1518 (R-58), mix bacteriano composto por $P$. fluorescens (BRM32111) e B. pyrrocinia (BRM32113) e mix de T. asperellum composto por (UFRA-T.06, UFRAT.09, UFRA-T.12, e UFRA-T.52) em plantas de grama esmeralda. O comprimento de cada autovetor é proporcional à variância obtida para os resultados de quantificação de cada variável. Método de inoculação por rega.

Todos os microrganismos, inoculados por rega, estimularam crescimento de grama esmeralda, em média de 58\% para AP, em 91\% MSR em relação ao controle (Figura 3). 0 aumento máximo foi para as plantas inoculadas com B. pyrrocinia (BRM32113), em média de 92\% para AP e 156\% de MSR. Os demais microrganismos induziram aumentos variando, em média, entre $85 \%$ e $25 \%$ para AP e entre $130 \%$ e $57 \%$ para MSR.

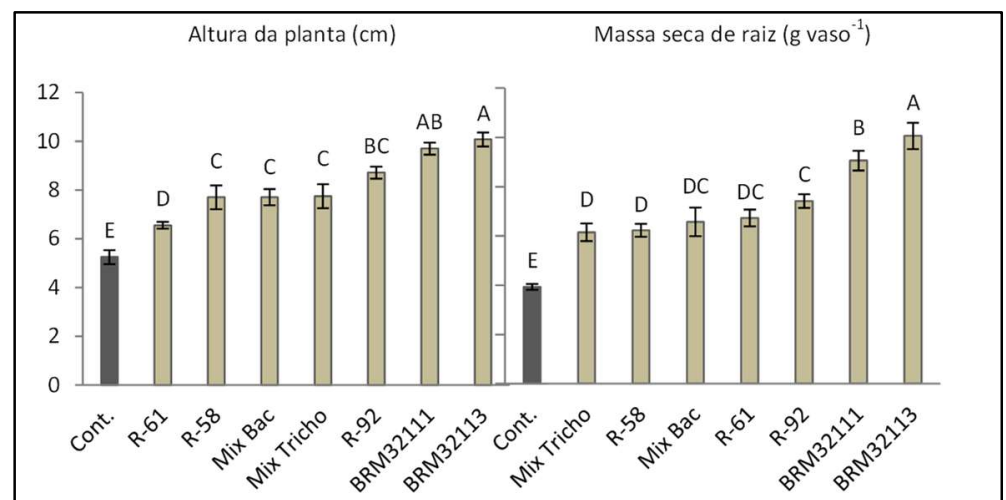

Figura 3: Altura de plantas e matéria seca de raiz (MSR) nos diferentes tratamentos: Controle, $P$. fluorescens (BRM32111), B. pyrrocinia (BRM32113), P. sabulilitoris strain GJMS-35 (R-92), B. thuringiensis YBT-1518 (R-61), B. thuringiensis YBT-1518 (R-58), mix bacteriano composto por P. fluorescens (BRM32111) e B. pyrrocinia (BRM32113) e mix de T. asperellum composto por (UFRA-T.06, UFRA-T.09, UFRA-T.12, e UFRA-T.52) em plantas de grama esmeralda. Inoculação por rêga. Colunas com letras diferentes denotam diferenças significativas entre os tratamentos $(p \leq 0,05$, teste de média Tukey). Os valores referem-se à média de quatro repetições \pm DP.

Ensaio II. Conforme ensaio I, o método de inoculação por rega e a rizobactéria $B$. pyrrocinia (BRM32113) apresentaram melhor incremento a promoção do crescimento da grama e no ensaio II foram comparados à adubação mineral. Todos os tratamentos inoculados induziram aumentos em altura de plantas $(\mathrm{AP})$, comparados aos não inoculados, exceto para o tratamento NP $\mathrm{K}$. Plantas inoculadas e cultivadas em substrato tiveram acréscimos de 65\% em AP, se comparadas ao tratamento não inoculado (Figura 4). 


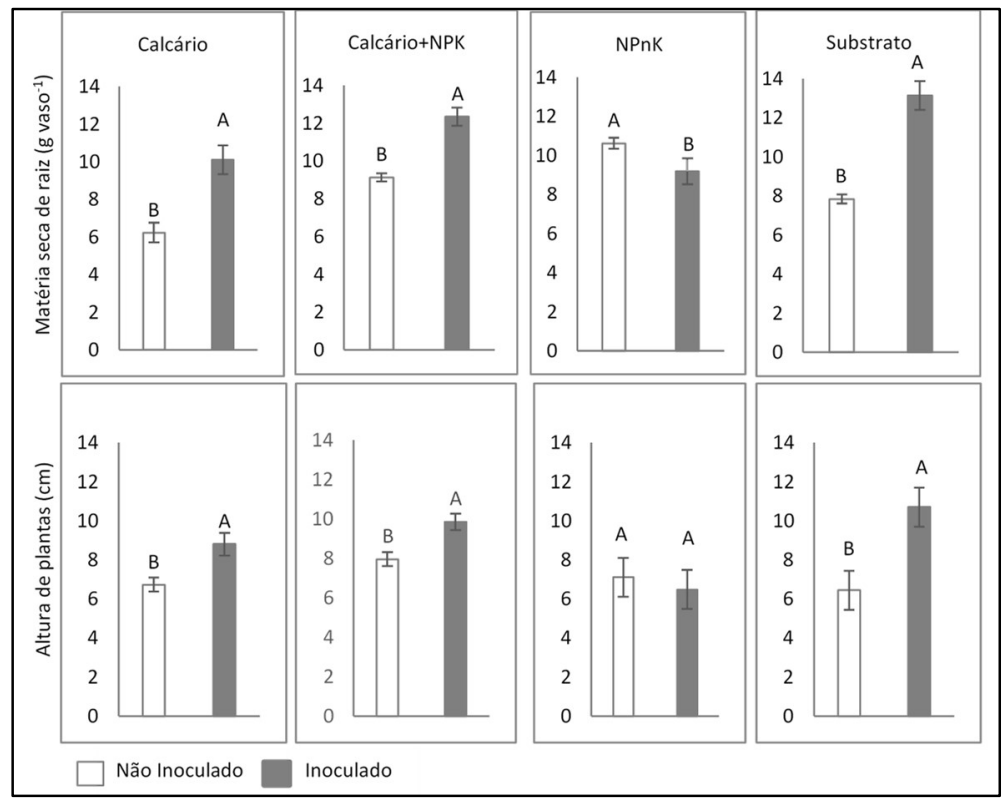

Figura 4: Efeitos da inoculação por rega de B. pyrrocinia na matéria seca de raiz (MSR) e altura de plantas (AP) em plantas de grama esmeralda. Colunas com letras diferentes denotam diferenças significativas entre os tratamentos ( $p$

$\leq 0,05$, teste de média Tukey). Os valores referem-se à média de cinco repetições \pm DP. Inoculados (com preenchimento) e não inoculados (sem preenchimento). N (ureia como fonte de nitrogênio); P (Superfosfato triplo como fonte de fósforo); $\mathrm{P}^{\mathrm{n}}$ (Fosfato de Araxá como fonte de fósforo); $\mathrm{K}$ (Cloreto de potássio como fonte de potássio).

Os teores de nutrientes em folhas de grama esmeralda foram influenciados positivamente pela inoculação com a rizobactéria B. pyrrocinia (BRM32113) (Tabela 2), exceto quando combinado ao uso do NPn K. Nas folhas, a rizobactéria induziu maiores acréscimos nos teores de nutrientes para os tratamentos calcário e substrato, em média, com 258 e 59\% para nitrogênio (N), 17 e 61\% para fosforo (P), 583 56\% para potássio (K), 12 e 86\% para cálcio (Ca) e 25 e 54\% para magnésio (Mg), quando comparados com plantas não inoculados. Porém, para o tratamento com NPn K, houve redução desses teores com quedas de até $40 \%$, no caso do nitrogênio $(\mathrm{N})$ permanecendo elevado apenas para teores de magnésio $(\mathrm{Mg})$, quando comparados com plantas não inoculados (Tabela 2).

A área de cobertura verde do solo sofreu influência positiva com a inoculação com rizobactéria $B$. pyrrocinia (BRM32113) nas plantas cultivadas em solo calcarizado (27\%) e em substrato (34\%) aos 45 dias se comparadas ao controle (Tabela 3). O tratamento utilizando apenas o substrato inoculado, obtiveram acréscimos de até $100 \%$, em média $55 \%$ superior ao tratamento NPnK, comparadas a avaliação inicial.

Tabela 2: Inoculação de B. pyrrocinia nos teores de nitrogênio $(\mathrm{N})$, fósforo $(\mathrm{P})$, potássio $(\mathrm{K})$, cálcio $(\mathrm{Ca})$ e magnésio $(\mathrm{Mg})$ em folhas.

\begin{tabular}{|c|c|c|c|c|c|c|c|c|}
\hline \multirow[t]{3}{*}{ Nutrientes } & \multicolumn{8}{|c|}{ Teores de Nutrientes em folhas $\mathrm{g} \mathrm{kg}^{-1}$} \\
\hline & \multicolumn{2}{|l|}{ Calcário } & \multicolumn{2}{|l|}{ Calcário+NPK } & \multicolumn{2}{|l|}{ NPnK } & \multicolumn{2}{|l|}{ Substrato } \\
\hline & $\mathrm{NI}$ & 1 & $\mathrm{NI}$ & 1 & $\mathrm{NI}$ & 1 & $\mathrm{NI}$ & 1 \\
\hline $\mathrm{N}$ & $6,55 \pm 0,99 d$ & $23,44 \pm 0,74 b^{*}$ & $30,01 \pm 0,37 a$ & $33,92 \pm 0,63 a^{*}$ & $8,93 \pm 0,63 c^{*}$ & $5,36 \pm 0,63 c$ & $14,58 \pm 0,96 b$ & $23,21 \pm 0,63 b^{*}$ \\
\hline$P$ & $1,83 \pm 0,01 b$ & $2,15 \pm 0,09 a^{*}$ & $2,19 \pm 0,04 a$ & $2,01 \pm 0,01 b$ & $1,88 \pm 0,03 b^{*}$ & $1,20 \pm 0,01 c$ & $1,34 \pm 0,01 c$ & $2,16 \pm 0,02 a^{*}$ \\
\hline K & $2,79 \pm 0,29 c$ & $4,42 \pm 0,29 b^{*}$ & $5,52 \pm 0,08 a$ & $5,13 \pm 0,08 a$ & $5,33 \pm 0,21 a^{*}$ & $3,70 \pm 0,14 c$ & $3,25 \pm 0,08 b$ & $5,07 \pm 0,14 a^{*}$ \\
\hline $\mathrm{Ca}$ & $5,79 \pm 0,53 a$ & $6,47 \pm 0,26 a^{*}$ & $4,75 \pm 0,39 b$ & $6,66 \pm 0,42 a^{*}$ & $4,73 \pm 0,06 b$ & $4,48 \pm 0,23 b$ & $1,60 \pm 0,05 c$ & $2,98 \pm 0,07 c^{*}$ \\
\hline $\mathrm{Mg}$ & $0,72 \pm 0,05 c$ & $0,9 \pm 0,01 \mathrm{~d}$ & $1,09 \pm 0,02 b$ & $1,29 \pm 0,02 c$ & $2,1 \pm 0,010 a$ & $3,36 \pm 0,48 a^{*}$ & $1,02 \pm 0,11 \mathrm{BC}$ & $2,59 \pm 0,03 b^{*}$ \\
\hline
\end{tabular}

Médias seguidas de asteriscos denotam diferenças significativas entre métodos (Inoculados (I) e não inoculados ( $\mathrm{NI}$ )). Os valores referem-se à média de cinco repetições ( $p \leq 0,05$, teste de média Tukey). Linhas com letras minúsculas diferentes denotam diferenças significativas dentre tratamentos. N (ureia como fonte de nitrogênio); P (Superfosfato triplo como fonte de fósforo); $\mathrm{P}^{\mathrm{n}}$ (Fosfato de Araxá como fonte de fósforo); $\mathrm{K}$ (Cloreto de potássio como fonte de potássio). 
Tabela 3: Inoculação de B. pyrrocinia na área de cobertura verde do solo aos $0,15,30$ e 45 dias após o plantio e inoculação (D.A.P).

\begin{tabular}{|c|c|c|c|c|c|c|c|c|}
\hline \multirow[t]{3}{*}{$\begin{array}{l}\text { D.A. } \\
\text { P }\end{array}$} & & & \multicolumn{2}{|c|}{$\begin{array}{l}\text { Área de cobertura verde } \\
\mathrm{cm}^{2}\end{array}$} & & & & \\
\hline & \multicolumn{2}{|l|}{ Calcário } & \multicolumn{2}{|c|}{ Calcário + NPK } & \multicolumn{2}{|l|}{ NPnK } & \multicolumn{2}{|l|}{ Substrato } \\
\hline & $\mathrm{NI}$ & 1 & $\mathrm{NI}$ & I & $\mathrm{NI}$ & 1 & $\mathrm{NI}$ & 1 \\
\hline 0 & $\begin{array}{l}149,16 \pm 9,2 \\
0 a\end{array}$ & $\begin{array}{l}148,75 \pm 8,96 \\
\text { a }\end{array}$ & $\begin{array}{l}150,13 \pm 12 \\
31 a\end{array}$ & $\begin{array}{l}150,83 \pm 11, \\
11 a\end{array}$ & $\begin{array}{l}150,42 \pm 10 \\
98 a\end{array}$ & $\begin{array}{l}149,26 \pm 12 \\
54 a\end{array}$ & $\begin{array}{l}149,30 \pm 12 \\
20 a\end{array}$ & $\begin{array}{l}149,94 \pm 12,0 \\
4 a\end{array}$ \\
\hline 15 & $\begin{array}{l}172,21 \pm 12, \\
90 \mathrm{~b}\end{array}$ & $\begin{array}{l}209,44 \pm 15,6 \\
2 b^{*}\end{array}$ & $\begin{array}{l}211,92 \pm 11 \\
01 a\end{array}$ & $\begin{array}{l}208,63 \pm 10 \\
01 \mathrm{~b}\end{array}$ & $\begin{array}{l}196,45 \pm 13 \\
08 a\end{array}$ & $\begin{array}{l}193,90 \pm 13, \\
88 \mathrm{~b}\end{array}$ & $\begin{array}{l}195,72 \pm 14 \\
65 a\end{array}$ & $\begin{array}{l}316,63 \pm 14,1 \\
5 a *\end{array}$ \\
\hline 30 & $\begin{array}{l}229,27 \pm 9,8 \\
7 \mathrm{~b}\end{array}$ & $\begin{array}{l}303,92 \pm 15,1 \\
4 a *\end{array}$ & $\begin{array}{l}264,52 \pm 14, \\
86 a\end{array}$ & $\begin{array}{l}270,32 \pm 13, \\
93 b\end{array}$ & $\begin{array}{l}215,04 \pm 11, \\
12 b\end{array}$ & $\begin{array}{l}209,09 \pm 9,3 \\
5 c\end{array}$ & $\begin{array}{l}214,27 \pm 11 \\
29 \mathrm{~b}\end{array}$ & $\begin{array}{l}308,82 \pm 14,3 \\
5 a^{*}\end{array}$ \\
\hline 45 & $\begin{array}{l}248,78 \pm 15 \\
63 b\end{array}$ & $\begin{array}{l}315,87 \pm 16,7 \\
3 a^{*}\end{array}$ & $\begin{array}{l}299,62 \pm 19 \\
47 a\end{array}$ & $\begin{array}{l}289,03 \pm 17 \\
81 a\end{array}$ & $\begin{array}{l}223,75 \pm 14 \\
61 \mathrm{~b}\end{array}$ & $\begin{array}{l}216,15 \pm 9,3 \\
5 b\end{array}$ & $\begin{array}{l}224,98 \pm 14, \\
40 \mathrm{~b}\end{array}$ & $\begin{array}{l}300,60 \pm 19,0 \\
0 a^{*}\end{array}$ \\
\hline
\end{tabular}

Médias seguidas de asteriscos denotam diferenças significativas entre métodos (Inoculados (I) e não inoculados (NI)). Os valores referem-se à média de cinco repetições ( $p \leq 0,05$, teste de média Tukey). Linhas com letras minúsculas diferentes denotam diferenças significativas dentre tratamentos. N (ureia como fonte de nitrogênio); P (Superfosfato triplo como fonte de fósforo); $\mathrm{P}^{\mathrm{n}}$ (Fosfato de Araxá como fonte de fósforo); $\mathrm{K}$ (Cloreto de potássio como fonte de potássio).

\section{DISCUSSÃO}

O efeito benéfico dos microrganismos em promover o crescimento vegetal é descrito por diversos autores (NASCENTE et al., 2017; KUMAR et al., 2018). Na produção comercial de tapetes de grama, após a colheita dos tapetes do ciclo anterior, objetiva-se um crescimento rápido dos estolões, raízes e parte aérea da grama, resultando na formação de tapetes, ao longo dos próximos ciclos, com qualidade satisfatória à comercialização (CARRIBEIRO, 2014). No presente estudo, estruturado em dois ensaios, a ação microbiana influenciou positivamente no crescimento de plantas de grama esmeralda (Z. japonica Steud.), evidenciado pelos maiores acúmulos de matéria seca de parte aérea e em altura de plantas.

No primeiro ensaio, todos os microrganismos estimularam o acúmulo de matéria seca total de plantas de grama esmeralda, principalmente quando a aplicação foi por rega (Tabela 1). Estudos mostram que para potencializar o crescimento pela associação planta-microrganismo, os experimentos devem ser selecionados em condições ecológicas específicas, com seleção massal de isolados, variados métodos de aplicação (PÉREZ-MONTAÑO et al., 2014; LOPES et al., 2018). Em Brachiaria, foi verificado grande variação na promoção do crescimento em função do método de aplicação do microrganismo, onde o método por rega também estimulou em maior ganho de matéria seca total, aumentos nos valores de área foliar e número de perfilhos (LOPES et al., 2018).

Melhores resultados obtidos pela inoculação por rega podem estar relacionados ao maior tempo de contato do microrganismo com o sistema radicular do gramado, se comparado ao método de inoculação por imersão. Neste caso, o maior tempo de contato com a rizosfera favorece o encontro físico entre a bactéria e a planta, promovendo o estabelecimento do quorum sensing, um mecanismo regulatório que permite a adaptação microbiana por meio de sinalização química à condições instáveis, essa compreensão de sinais permite que células bacterianas individuais percebam a si e a outros indivíduos adaptando-se ao ambiente de crescimento, regulando o tamanho das populações, favorecendo a colonização inicial do tecido vegetal e favorecendo a expressão de genes associados a promoção do crescimento da plantas hospedeira (OLIVEIRA et al., 2003). 
Em grama, as variáveis e paramentos utilizados para avaliar crescimento ainda não são padronizados, assim nesse estudo adotou-se a análise de componentes principais (PCA) a fim de identificar as componentes principais (PC's) necessárias para explicar a variância total dos parâmetros examinados (KAISER, 1960). Nesta pesquisa, maior percentual da variância total foi retida para PC1 com maiores contribuições geradas pelas variáveis de análise MSR e AP (Figura 1). A importância desta avaliação está na possibilidade de descarte de variáveis que contribuam pouco para a discriminação dos tratamentos, reduzindo, dessa forma, mão-deobra, tempo e custos dispendidos, na experimentação agrícola (CRUZ et al., 1997), oficializada pelos vetores tendenciosos ao PC1 em sentido horizontal (Figura 2), que revela maior interação das variáveis MSR e AP com grupo formado por $P$. fluorescens (BRM32111) e B. pyrrocinia (BRM32113), uma vez que quanto maiores os vetores, maior a influência da variável e, quanto mais agrupadas as variáveis e indivíduos, maior a correlação entre si (VICINI et al., 2005).

A análise de variância dos dados de MSR e AP em resposta da ação de $P$. fluorescens e $B$. pyrrocinia (Figura 3) inoculadas por rega, configura maiores acréscimos obtidos por B. pyrrocinia ao acúmulo de MSR. Em pesquisas semelhantes, está rizobactéria também beneficiou o sistema radicular em plantas de arroz, induzindo aumentos de matéria seca (ESTRADA et al., 2013; NASCENTE et al., 2017; RÊGO et al., 2018). Em plantas de grama bermuda, quando tratadas com mistura de rizobactérias, o sistema radicular também apresentou maior desenvolvimento, com maiores incrementos, tanto em matéria seca como em comprimento de raízes (COY et al., 2014).

Os mecanismos envolvidos na promoção do crescimento, induzidos por rizobactérias, ocorrem tanto pela transferência de moléculas sintetizadas pela bactéria para a planta como pelo incremento na absorção ou aumento da disponibilidade de certos elementos nutricionais, a produção de fitormônios reguladores do crescimento também faz parte do metabolismo de diversas espécies de rizobactérias (OLIVEIRA et al., 2003; GOMES et al., 2016).

Rizobactérias também potencializam a fertilidade dos solos por meio de processos que aumentam a disponibilidade de nutrientes, através da fixação e mobilização de nitrogênio, fósforo e potássio. Para solubilizar fosfato, utilizam dois mecanismos, primeiro liberando ácidos orgânicos e afetando a mobilidade do fósforo, através de interações iônicas, e segundo por meio de fosfatasses, que ajudam a desvincular os grupos de fosfato da matéria orgânica (RACHID et al., 2016). Na disponibilização de nitrogênio, microrganismos fixam o $\mathrm{N}_{2}$ atmosférico na forma de amônia $\left(\mathrm{NH}_{3}\right)$ através do seu processo metabólico normal. Algumas bactérias tem a capacidade de infectar as raízes e induzir a formação de nódulos em plantas leguminosas, já em gramíneas podem atuar em associações endolíticas, sofrendo menos competição do que as bactérias presentes no solo, disponibilizando, parte do $\mathrm{N}$ diretamente para a planta (BALACHANDAR et al., 2006; RACHID et al., 2016). Para disponibilizar o potássio, os rizobactérias atuam diretamente sobre a estrutura dos minerais silicatados da fração de argila e silte do solo, por exemplo, oxidam o Fe a partir da biotita, liberando $\mathrm{K}$ e o Fe é utilizado como doador de elétron para seu metabolismo como fonte como de energia, além disso, ocorre uma elevada produção de ácidos orgânicos quelatos de íons Si e Al, disponibilizando o potássio e liberando $\mathrm{H}^{+}$na solução do solo (SHERLOBOLINA et al., 2014) 
No segundo ensaio desta pesquisa, utilizando o método de inoculação por rega e a rizobactéria $B$. pyrrocinia (BRM32113) selecionada inicialmente, foram comparados à adubação mineral. A inoculação de $B$. pyrrocinia favoreceu acréscimos em AP em todos os tratamentos, exceto, quando a adubação mineral do solo utiliza fosfato de Araxá como fonte de fósforo (Figura 4). É provável que as reduções na eficiência das rizobactérias em promover crescimento em plantas adubadas com utilizando uma fonte fósforo natural $\left(\mathrm{NP}^{\mathrm{n}} \mathrm{K}\right)$ possam estar relacionadas ao fato de ocorrer concentrações tóxicas de alguns metais, liberadas durante a solubilização de fosfato natural, podendo afetar o desenvolvimento, a fisiologia e o metabolismo, por meio de distúrbios funcionais, desnaturando proteínas e destruindo a integridade da membrana celular de microrganismos benéficos (SOUCHIE et al., 2005; SILVEIRA et al., 2007).

De maneira geral, os fertilizantes fosfatados, dependendo do seu material de origem, podem apresentar teores de metais, bem como resíduos ácidos, produtos de sua elaboração (VAN KAUWENBERGH, 2002). O fosfato de Araxá, em sua origem ígnea, apresenta pequeno grau de substituição do $\mathrm{PO}_{4}^{-3}$ pelo $\mathrm{CO}_{3}^{2-}$ em sua estrutura cristalina, sendo, por isto, pouco solubilizado (LEHR et al., 1972). Avaliando teores de metais em diferentes fontes fosfatadas, foram determinados teores mais elevados de cádmio em fosfatos naturais por Bizarro et al. (2008). Teores de cádmio, chumbo e cromo também foram detectados em fosfato monoamônio (GONÇALVES JUNIOR et al., 2015).

Melhores resultados foram alcançados na ausência da adubação (Figura 4). Plantas inoculadas e cultivada em substrato, os resultados foram superiores tanto em AP, como nos teores de nitrogênio (N), fósforo (P), potássio (K), cálcio (Ca) e magnésio (Mg), em folhas. Lopes et al. (2018) também verificaram maior crescimento em Brachiaria brizantha na ausência do fertilizante.

Quanto às condições do meio, as rizobactérias contribuem mais efetivamente em condições pobres de nutrientes, havendo pressão seletiva sobre elas em condições de nutrição mais adequada (COSTA et al., 2013). A inoculação com rizobactérias promotoras do crescimento, também favoreceu acréscimos na concentração de nitrogênio em Brachiaria quando não associadas ao uso de fertilizantes (LOPES et al., 2018).

Com a disponibilidade de nutrientes ocorre um aumento na população microbiana, favorecendo o crescimento vegetal com acentuado aumento na produção de exsudados radiculares. Os mecanismos de indução microbiana da exsudação radicular não são bem conhecidos, mas uma das possibilidades é que os microrganismos metabolizam rapidamente o C liberado, criando um gradiente de concentração que favorecem novas exsudações (SILVEIRA et al., 2007). Em gramíneas, tanto a liberação de exsudados como entrelaçando pequenos torrões constituem agente agregador de partículas nos solos, formando estruturas maiores, contribuindo para formação e estabilidade de agregados, boa aeração e maior capacidade de infiltração de água, contribuindo também para a manutenção da matéria orgânica (BRADY et al., 2013; SILVA et al., 2019).

\section{CONCLUSÕES}

Todos os microrganismos promoveram o crescimento em grama esmeralda. A rizobactéria Burkholderia pyrrocinia (BRM32113) inoculada via rega é o mais promissor promotor de crescimento em 
grama esmeralda. Rizobactéria B. pyrrocinia (BRM32113) se constitui alternativa potencial ao manejo nutricional do solo, podendo contribuir para reduções no uso dos fertilizantes químicos, visando sistemas agrícolas mais sustentáveis com níveis satisfatórios de produtividade.

\section{REFERÊNCIAS}

BACKES, C.; LIMA, C. P.; BÔAS, R. L. V.; FERNANDES, D. M.. Resultados de pesquisas sobre a produção de grama: resistência e espessura de corte de tapetes. In: GODOY, L. J. G.; MATEUS, C. M. D.; BACKES, C.; BOAS, R. L. V.. Tópicos atuais em gramados. In: SIMPÓSIO SOBRE GRAMADOS, 2. Anais. Botucatu: FEPAF, 2010. p.82-91.

BALACHANDAR, D.; SANDHIYA, G. S.; SUGITHA, T. C. K.; KUMAR, K.. Flavonoids and growth hormones influence endophytic colonization and in plant nitrogen fixation by a diazotrophic Serratia sp. in rice. World Journal of Microbiology and Biotechnology, Oxiford, v.22, n.7, p.707712, 2006. DOI: https://doi.org/10.1007/s11274-005-9094-0

BETTIOL, W.; MORANDI, M. A. B.. Biocontrole de doenças de plantas: uso e perspectivas. Jaguariúna: Embrapa Meio Ambiente, 2009.

BIZARRO, V. G.; MEURER, E. J.; TATSCH, F. R. P.. Teor de cádmio em fertilizantes fosfatados comercializados no Brasil. Ciência rural, Santa Maria, v.38, n.1, p.247-250, 2008. DOI: http://dx.doi.org/10.1590/S0103-84782008000100041

BRADY, N. C.; WEIL, R. R.. Elementos da natureza e propriedades dos solos. 3 ed. Porto Alegue: Bookman, 2012.

CARRIBEIRO, L. S.. Compactação e lâminas de água do solo para a colheita de tapetes de grama. Tese (Doutorado em agronomia/irrigação e drenagem) - Universidade Estadual Paulista Júlio de Mesquita Filho, São Paulo, 2014.

CASTRO, G. L. S.. Rizobactérias promovem crescimento, aliviam os efeitos do déficit hídrico e reduzem antracnose em mudas de açaizeiro. Tese (Doutorado em Agronomia) Universidade Federal Rural da Amazônia, Belém, 2018.

CHAGAS, L. F. B.; JUNIOR, A. F. C.; CASTRO, H. G.. Phosphate solubilization capacity and indole acetic acid production by Trichoderma strains for biomass increase on basil and mint plants. Brazilian Journal of Agriculture, São Paulo, v.92, n.2, p.176-185, 2017

COSTA, P. B. da; BENEDUZI, A.; SOUZA, R.; SCHOENFELD, R.; VARGAS, L. K.; PASSAGLIA, L. M. P.. The effects of different fertilization conditions on bacterial plant growth promoting traits: guidelines for directed bacterial prospection and testing. Plant and Soil, Camberra, v.368, n.1-2, p.267-280, 2013.

COY, R. M.; HELD, D. W.; KLOEPPER, J. W.. Rhizobacterial inoculants increase root and shoot growth in 'Tifway'hybrid bermudagrass. Journal of Environmental Horticulture, Virginia Beach, v.32, n.3, p.149-154, 2014.

CRAVO, M. S.; VIÉGAS, I. J. M.; BRASIL, E. C.. Recomendações de adubação e Calagem para o Estado do Pará. Belém: Embrapa Amazônia Oriental, 2007.
CRUZ, C. D.; REGAZZI, A. J.. Modelos Biométricos Aplicados ao Melhoramento Genético. 2 ed. Viçosa: UFV, 1997.

ESTRADA, G.; BALDANI, V. L. D.; OLIVEIRA, D. M.; URQUIAGA, S.; BALDANI, J. I.. Selection of phosphate-solubilizing diazotrophic Herbaspirillum and Burkholderia strains and their effect on rice crop yield and nutrient uptake. Plant and Soil, Camberra, v.369, n.1-2, p.115-129, 2013.

GODOY, L. J. G.; BÔAS, R. L. V.. Nutrição e adubação para gramados. In: SIMPÓSIO SOBRE GRAMADOS, 1. Anais. Botucatu: UNESP, 2003.

GOMES, E.; SILVA, U. D. C.; PAIVA, C.; LANA, U. D. P.; MARRIEL, I.; SANTOS, V. L.. Microrganismos promotores do crescimento de plantas. Sete Lagoas: Embrapa Milho e Sorgo, 2016.

GONÇALVES JUNIOR, A. C.; YOSHIHARA, M. M.; CARVALHO, E. A.; STREY, L.; DE MORAES, A. J.. Teores de nutrientes e metais pesados em plantas de estragão submetidas a diferentes fertilizações. Revista Ciência Agronômica, Fortaleza, v.46, n.2, p.233-240, 2015.

GUPTA, G.; PANWAR, J.; AKHTAR, M. S.; JHA, P. N. Endophytic Nitrogen-Fixing Bacteria as Biofertilizer. In: Sustainable Agriculture Reviews, Springer, v.11, p.183-221, 2012. DOI: https://doi.org/10.1007/978-94-007-5449-2 8

KAISER, H. F.. The varimax criterion for analytic rotation in factor analysis. Psychometrika, New York, v.23, n.3, p.187200, 1960. DOI: https://doi.org/10.1007/BF02289233

KUMAR, P.; THAKUR, S.; DHINGRA, G. K.; SINGH, A.; PAL, M.; HARSHVARDHAN, K.; DUBEY, R. C.; MAHESHWARI, D. K.. Inoculation of siderophore producing rhizobacteria and their consortium for growth enhancement of wheat plant. Biocatalisys and Agricultural Biotechnology, Amsterdam, v.15, p.264-269, 2018. DOI: https://doi.org/10.1016 /j.bcab.2018.06.019

LEHR, J. R.; McCLELLAN, G. H.. A revised laboratory reactivity scale for evaluating phosphate rocks for direct application. Nashville: National Fertilizer Development Center, 1972.

LOPES, M. J. S.; FILHO, M. B. D.; CASTRO, T. H. R.; FILIPPI, M C. C.; SILVA, G. B.. Effect of Pseudomonas fluorescens and Burkholderia pyrrocinia on the growth improvement and physiological responses in Brachiaria brizantha. American Journal of Plant Sciences, v.9, n.2, p.250, 2018. DOI: https://doi.org/10.4236/ajps.2018.92021

MACHADO, D. F. M.; PARZIANELLO, F. R.; SILVA, A. C. F.; ANTONIOLLI, Z. I.. Trichoderma no Brasil: O fungo e o bioagente. Revista de Ciências Agrárias, Lisboa, v.35, n.1, p.274-288, 2012 
NASCENTE, A. S.; DE FILIPPI, M. C. C.; LANNA, A. C.; SOUSA, T. P.; SOUZA, A. C. A.; LOBO, V. L. S.; SILVA, G. B.. Effects of beneficial microorganisms on lowland rice development. Environmental Science and Pollution Research, Berlim, v.24, n.32, p.25233-25242, 2017. DOI: https://doi.org/10.1007/s11356-017-0212-y

OLIVEIRA, A. L. M.; URQUIAGAS, S.; BALDANI, J. L.. Processos e mecanismos envolvidos na influência de microrganismos sobre o crescimento vegetal. Seropédia: Embrapa Agrobiologia, n.161 p.40, 2003.

PÉREZ-MONTAÑO, F.; ALÍAS-VILLEGAS, C.; BELLOGÍN, R. A.; DEL CERRO, P.; ESPUNY, M. R.; JIMÉNEZ-GUERRERO, I.; F.J. LÓPEZ-BAENA; OLLERO, F.J.; CUBO, T.. Plant growth promotion in cereal and leguminous agricultural important plants: from microorganism capacities to crop production. Microbiological research, v.169, n.5-6, p.325-336, 2014. DOI: https://doi.org/10.1016/j.micres.2013.09.011

PETERSON, K.; ARNOLD, K. S. BREMER, D.. Custom Light Box for Digital Image Turfgrass Analysis. K- State Turfgrass Research, 2011.

RASHID, M. I.; MUJAWAR, L. H.; SHAHZAD, T.; ALMEELBI, T.; ISMAIL, I. M.; OVES, M.. Bacteria and fungi can contribute to nutrients bioavailability and aggregate formation in degraded soils. Microbiological Research, v.183, p.26-41, 2016. DOI: https://doi.org/10.1016/i.micres.2015.11.007

RÊGO, M. C. F.; ILKIU-BORGES, F.; FILIPPI, M. C. C. D.; GONÇALVES, L. A.; SILVA, G. B. D.. Morphoanatomical and biochemical changes in the roots of rice plants induced by plant growth-promoting microorganisms. Journal of Botany, v. 2014, p.10, 2014. DOI:

http://dx.doi.org/10.1155/2014/818797

RÊGO, M. C.; CARDOSO, A. F.; DA C FERREIRA, T.; DE FILIPPI, M. C.; BATISTA, T. F.; VIANA, R. G.; DA SILVA, G. B.. The role of rhizobacteria in rice plants: growth and mitigation of toxicity. Journal of Integrative Agriculture, v.17, n.12, p.2636-2647, 2018. DOI: https://doi.org/10.1016/S20953119(18)62039-8

SANTOS JUNIOR, C. E. F.. Adubação nitrogenada e calagem na produção de gramas Esmeralda e Bermuda. Dissertação (Mestrado em Produção Vegetal) - Universidade Estadual do
Norte Fluminense Darcy Ribeiro, Rio de janeiro, 2011.

SHELOBOLINA, E.; RODEN, E.; BENZINE, J.; XIONG, M. Y. Using phyllosilicate-fe (ii)-oxidizingsoil bacteria to improve fe and K plant nutrition. U.S. Patent Application n.14/209,509. 2014

SILVA, F. C. S.. Manual de análises químicas de solos, plantas e fertilizantes. 2 ed. Brasília: Embrapa Informação Tecnológica; Rio de Janeiro: Embrapa Solos, 2009.

SILVA, J. C.; TORRES, D. B.; LUSTOSA, D. C.; FILIPPI, M. C. C.; SILVA, G. B.. Rice sheath blight biocontrol and growth promotion by Trichoderma isolates from the Amazon. Revista de Ciências Agrárias, v.55, n.4, p.243-250, 2012. DOI: http://dx.doi.org/10.4322/rca.2012.078

SILVA, P. L. F.; DE OLIVEIRA, F. P.; PEREIRA, W. E.; BORBA, J. D. M.; TAVARES, D. D.; SANTOS, T. E. D.; MARTINS, A. F. Estoques de carbono e retenção hídrica em biomassa de gramíneas no agreste da paraíba. Revista Brasileira de Engenharia de Biossistemas, v.13, n.2, p.155-167, 2019. DOI: http://dx.doi.org/10.18011/bioeng2019v13n2p155-167

SILVA, S. B.. Análise de solo. Belém: Universidade Federal Rural da Amazônia, 2003.

SILVEIRA, A. P. D.; FREITAS, S. S.. Microbiota do solo e qualidade ambiental. Campinas: Instituto Agronômico, 2007.

SOUCHIE, E. L.; CAMPELLO, E. F. C.; SAGGIN-JÚNIOR, O. J.; SILVA, E. M. R.. Mudas de espécies arbóreas inoculadas com bactérias solubilizadoras de fosfato e fungos micorrízicos arbusculares. Floresta, Curitiba, v.35, n.2, 2005. DOI: http://dx.doi.org/10.5380/rf.v35i2.4620

TEDESCO, M. J.; GIANELLO, C.; BISSANI, C. A.; BOHNEN, H.; VOLKWEISS, S. J.. Análise de solo, plantas e outros materiais. 2 ed. Porto Alegre: UFRGS, Departamento de Solos, 1995.

VAN KAUWEnBERGH, S. J.. Cadmium Content of Phosphate Rocks and Fertilizers. Chennai: IFA, 2002.

VICINI, L.; SOUZA, A. M.. Análise multivariada da teoria à prática. Santa Maria: UFSM, 2005.

A CBPC - Companhia Brasileira de Produção Científica (CNPJ: 11.221.422/0001-03) detém os direitos materiais desta publicação. Os direitos referem-se à publicação do trabalho em qualquer parte do mundo, incluindo os direitos às renovações, expansões e disseminações da contribuição, bem como outros direitos subsidiários. Todos os trabalhos publicados eletronicamente poderão posteriormente ser publicados em coletâneas impressas sob coordenação da Sustenere Publishing, da Companhia Brasileira de Produção Científica e seus parceiros autorizados. Os (as) autores (as) preservam os direitos autorais, mas não têm permissão para a publicação da contribuição em outro meio, impresso ou digital, em português ou em tradução. 